\title{
Usos de [la] locura: hacia el reconocimiento de nuevas lógicas interpretativas del sufrimiento humano
}

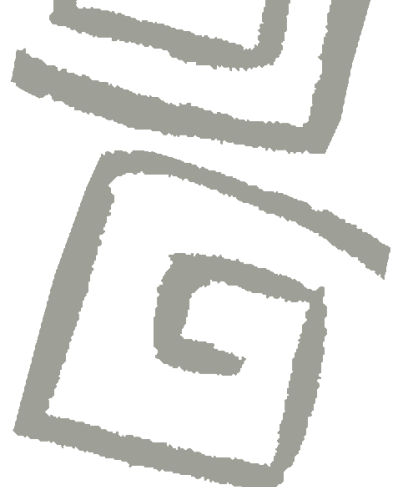

\author{
Uses of madness: towards the recognition of new \\ interpretations of human suffering
}

Miguel Salas Soneira ${ }^{1}$

${ }^{1}$ Doctor en Ciencias de la Educación. Profesor colaborador, Universidad Oberta de Catalunya, España. $\$ (iD)
RESUMEN El presente artículo aborda la controversia asociada al constructo esquizofrenia/psicosis/locura, señalando la necesidad de admitir la multiplicidad de experiencias e interpretaciones que se ponen en juego mediante su uso. La pluralidad, la complejidad intrínseca al fenómeno, la disconformidad en sus posibles significados y el valor de las experiencias en primera persona, se indican como dimensiones cuyo reconocimiento resulta indispensable tanto en la comprensión del malestar como en su enfrentamiento socioeducativo. A partir de entrevistas realizadas entre septiembre de 2013 y mayo de 2014 a seis personas diagnosticadas al menos de esquizofrenia, que participaron de forma consentida e informada, se abordan dichas dimensiones y se revisa la locura desde una perspectiva queer, como posible lugar de enunciación política que permita habilitar nuevos tránsitos y formas de circulación social a los sujetos de la aflicción.

PALABRAS ClAVES Salud Mental; Poder (Psicología); Reconocimiento (Psicología); Queers; Educación; España.

\begin{abstract}
This article addresses the controversy associated with the construct schizophrenia/psychosis/madness, indicating the need to acknowledge the multiplicity of experiences and interpretations which arise through the use of the construct. The plurality and complexity intrinsic to the phenomenon, the discrepancies in its possible meanings and the value of first-hand experience are indicated as aspects whose recognition is indispensable to both understanding suffering and confronting it socioeducationally. Using interviews carried out in September 2013 and May 2014 with six people diagnosed at least with schizophrenia, who gave their informed consent to participate, these dimensions are explored. Additionally, madness is examined from a queer perspective as a possible space of political expression that permits new paths and forms of social circulation among those afflicted.
\end{abstract}

KEY WORDS Mental Health; Power (Psychology); Recognition (Psychology); Queers; Education; Spain. 


\section{INTRODUCCIÓN: UN CONCEPTO EN ESENCIA CONTROVERTIDO}

Geekie y $\operatorname{Read}^{(1)}$ sostienen que los términos esquizofrenia, psicosis y locura se refieren esencialmente a los mismos tipos de experiencias, a pesar de que lo hagan partiendo de puntos de vista diferentes. En cuanto a los dos primeros, mantienen que ambos sitúan dichas experiencias en un marco clínico predominantemente psiquiátrico, mientras que el último, la locura, lo hace en el plano de la experiencia humana cotidiana tanto ordinaria, como extraordinaria. Esta perspectiva ha sido defendida, entre otros, por autores como Álvarez ${ }^{(2)}$, que pone de manifiesto la tendencia de la mayoría de las invenciones nosológicas elaboradas sobre el sufrimiento mental humano de encorsetar la locura dentro del modelo de patología médica; o por Canals ${ }^{(3)}$, quien enfatiza además la idea de que el uso de los sinónimos clínicos de la locura tiende a ocultar la alteridad expresada en dicho término.

En la obra de Geekie y Read(1) se argumenta cómo es precisamente la dimensión popular que se incorpora en el uso de la palabra locura, la que posibilita contribuciones significativas por parte de todas las personas, incluidas aquellas que sufren o vivencian directamente tales experiencias. De este modo:

\begin{abstract}
Al usar el término "locura" la experiencia es arrancada de las garras de una élite formada por un puñado de expertos en la "esquizofrenia" y la "locura" pasa a ser mostrada como un aspecto de la condición humana sobre el cual todos podemos opinar, en lugar de como una enfermedad médica con un título oscuro derivado del griego o el latín.
\end{abstract}

Según este enfoque, los términos clínicos tenderían a limitar de manera innecesaria e inútil la participación en las discusiones acerca de las experiencias relacionadas con este fenómeno. Dicho aspecto resulta de especial interés para el propósito que aquí se plantea pues, de lo que se trata es de intentar situar en un plano de simetría diferentes saberes acerca de esta cuestión, con el fin de profundizar en algunas de sus dimensiones más significativas ${ }^{(4,5,6,67)}$. En cualquier caso, se coincide en que es conveniente no dejar de lado a aquellas personas que pueden realizar contribuciones valiosas para su comprensión $y$, menos aún, a quienes la experimentan significativamente en primera persona.

Se ha afirmado que existe un tenue cuando no nulo acuerdo entre científicos y profesionales, sobre qué constituye la experiencia de la locura o el modo más adecuado de denominarla ${ }^{(2,8,9,10)}$. Incluso, a pesar de tener a disposición los mismos resultados provenientes de la investigación, no existen actualmente evidencias científicas claras y definitivas que permitan indicar cuál de las posibles conceptualizaciones de la locura es la "correcta"(11). Tampoco se dispone de conclusiones fiables acerca de la naturaleza "real" de experiencias inusuales tales como oír voces o sentirse suspicaz, sus causas, o la mejor manera de abordar las problemáticas que, en ocasiones, conllevan ${ }^{(12,13)}$.

Tal vez, como señala Wittgenstein ${ }^{(14)}$, no sea siquiera posible no dotar de sentido y significado una experiencia, un fenómeno o un concepto dados, pues tal es en parte la empresa de la ciencia, sino pretender que tal o cual definición sea la "correcta". Sin tener relación con algún objetivo o meta determinados -que, obviamente pueden ser dispares y hasta antagónicos-, parece poco probable alcanzar cualquier tipo de acuerdo con pretensiones universales. Sin embargo, en lo que sí parece haber un cierto consenso es en que concretamente la esquizofrenia ha sido objeto, y continúa siéndolo, de un amplio espectro de explicaciones y definiciones que con frecuencia se encuentran enfrentadas ${ }^{(2)}$.

En este contexto y del mismo modo que sucede con el término "esquizofrenia", el concepto de psicosis tampoco ofrece una solución satisfactoria a la controversia. Además, aun tratándose de un término comúnmente empleado en nuestra sociedad para describir experiencias de sufrimiento psíquico, lo cierto es que muchas personas no se encuentran cómodas con esta denominación ${ }^{(11)}$. 
Con el objetivo de avanzar en la descodificación de los significados que encierran las variadas formas de nombrar experiencias complejas y heterogéneas -como vivir estados de ánimo extremos, escuchar voces, etc.-, conviene revisar la cuestión del uso de los términos, su importancia en el debate y apuntar algunas condiciones para el reconocimiento de una multiplicidad de interpretaciones posibles.

Según el filósofo y lingüista austríaco Wittgenstein, las palabras usadas en ciencia son recipientes capaces de contener y transmitir significado y sentido con relación a hechos descriptibles que ocurren en un lugar, duran un cierto tiempo, etc. En todo caso, el tipo de valoración de que son susceptibles las palabras, es siempre relativa a dichos hechos y al uso que de ellas se hace con relación a ellos. Por tanto, un término no es correcto o incorrecto, bueno o malo, adecuado o inadecuado per se, sino que depende de su función y su uso, es decir, de cómo se relacione con los hechos que describe y a que se refiere, con sus metas y objetivos. En este sentido, las palabras están a priori exentas de todo juicio de valor ético o absoluto ya que "en la medida en que nos refiramos a hechos y proposiciones, solo hay valor relativo y, por tanto, corrección y bondad relativas" (14).

A tenor de estos planteamientos, Geekie y $\operatorname{Read}^{(1)}$ han tratado de resolver la controversia terminológica de la esquizofrenia/ psicosis/locura, acudiendo precisamente a la filosofía de Wittgenstein y sus desarrollos posteriores, de los que recogen una serie de principios que pueden aplicarse al debate. En resumen, su propuesta consiste en que las palabras locura, esquizofrenia, psicosis, etc., tienen funciones diferentes y que, para conocer su significado, es necesario prestar atención al uso que de ellas se hace y no tanto a su definición. En consecuencia, más allá de una definición u otra, es justamente el modo en que un término es empleado y la manera en que funciona, lo que determina su significado.

Esta postura supone que la multiplicidad de teorías antagónicas sobre la naturaleza de la esquizofrenia no es un fenómeno aislado o fortuito, ni el simple reflejo de una etapa en la evolución del concepto, sino que representa una cualidad intrínseca del concepto en sí. Para los autores, la controversia en que se ha visto inmersa esta cuestión desde su mismo origen $-y$ que no muestra indicio alguno de remitir-, les hace sospechar que existen sobradas razones para defender que se trata de una característica de la idea misma de locura, más allá del término concreto que se decida adoptar. Esto sugiere algo del orden de la apertura a lo diferente, de la tentativa por admitir formulaciones variadas del fenómeno que, más allá de la establecida por la narrativa biomédica, puedan contribuir a avanzar en su interpretación, comprensión y afirmación.

\section{ACERCA DE LA INVESTIGACIÓN}

Este artículo se enmarca parcialmente en el trabajo de tesis doctoral ${ }^{(15)}$ de quien suscribe, cuya investigación empírica, de orientación cualitativa, apoya los argumentos teóricos expresados en lo que sigue. Desde una perspectiva dialógica, se obtuvieron seis relatos comunicativos en los que las personas participantes narraron, desde su punto de vista y en sus propios términos, lo que para ellos y ellas ha significado y/o representa la locura/esquizofrenia/psicosis en sus vidas. Como técnica de producción de información, las historias de vida fueron diseñadas atendiendo a los criterios de diferencialidad y variación expresados por Bertaux ${ }^{(16)}$ y grabadas en audio entre los meses de septiembre de 2013 y mayo de 2014. Tras su transcripción, el procesamiento del conjunto de los datos se llevó a cabo mediante el programa de análisis cualitativo Atlas ti.

Tal y como se recoge en el documento de consentimiento informado firmado voluntariamente por todas las personas participantes, se asignó a cada cual un nombre ficticio a fin de preservar la confidencialidad. Hay que advertir que, si bien las restricciones de espacio impiden aquí profundizar en las diferentes interpretaciones aportadas, alternativamente se 
expondrán algunos ejemplos ilustrativos de los testimonios recogidos. A través de ellos se tratará de dar cuenta de la necesidad de reconocer nuevas formas interpretativas para el sufrimiento humano.

\section{FORMAS DE RECONOCIMIENTO}

Se ha insistido en que el paisaje de la locura hace tiempo que se encuentra reordenado por las categorías diagnósticas. No obstante, esto conduce con frecuencia a las personas etiquetadas a una posición que puede ser considerada subalterna ${ }^{(17)}$ en la medida en que su reconocimiento parte de la imposición de una identidad patológica o deteriorada que se traduce en un trato cosificador, en la negación de la subjetividad, la narrativa y el saber de las personas afligidas. Butler ha señalado cómo lo humano se concibe de forma diferencial en función de determinados criterios o patrones relacionados estrechamente con un régimen preciso: el de la normalidad. Por ejemplo, dependiendo de la raza y la visibilidad de dicha raza, de la etnicidad y su categorización, del sexo y su verificación perceptiva, la morfología y el modo en que ésta es legitimada, etc., se produce el efecto de que "algunos humanos son reconocidos como menos que humanos y dicha forma de reconocimiento con enmiendas no conduce a una vida viable ${ }^{\prime \prime(18)}$.

En este sentido, advierte que si los proyectos de reconocimiento disponibles "son aquellos que 'deshacen' a la persona al conferirle reconocimiento, o que la 'deshacen' al negarle reconocimiento, entonces el reconocimiento se convierte en una sede del poder mediante la cual se produce lo humano de forma diferencial"(18). Siguiendo este razonamiento cabe preguntarse ¿qué sucede cuando experiencias humanas como la escucha de voces o los pensamientos extremadamente suspicaces son categorizados bajo la rúbrica del trastorno o la enfermedad mental?, ¿qué consecuencias tiene este hecho para el sujeto rotulado con catalogaciones como la de esquizofrenia paranoide o trastorno bipolar?, ¿qué reconocimiento se le confiere o qué es lo que se destaca o niega mediante estas etiquetas?

Basten tres testimonios para esbozar una idea general del impacto del diagnóstico en la subjetividad de una persona. Cuenta Uxía que, en el marco de la atención especializada, tiende a considerarse a quien padece la aflicción como

...una especie mueble. Ahora está este
sujeto, humano o no tan humano, que
hay que moverlo de aquí para allí.
Entonces, ese es el objetivo, hay que
cumplirlo sea como sea y por encima
de la voluntad o de la actitud de esa
persona.

Por su lado, Xián, cuya vida entre los muros de un hospital psiquiátrico se dilataría por más de veinte años, considera que "una vez entras en el manicomio ya eres un esquizofrénico, no eres. Eres una enfermedad, eres un montón, eres un grupo". Sabela, a su vez, explica la degradación del yo por la vía del diagnóstico como:

Lo más bajo, lo que no se le debía prestar importancia. O sea, había que negar su existencia. A parte de lo que había, de lo que yo creía, estaba lo que veían los demás. Entonces yo era catalogado, catalogada de lo peor y no quería. O sea, puedo estar un poco loca pero no he sido de lo peor.

Aunque los problemas del lenguaje y los distintos sentidos que encierra siempre abarcan cuestiones ideológicas y, en consecuencia, de poder, "es preciso no olvidar que hay un movimiento dinámico entre pensamiento, lenguaje y realidad del cual, si se asume bien, resulta una creciente capacidad creadora" $^{\prime(19)}$. Este aspecto es relevante, ya que la forma en que operan relatos como el biomédico bloquean a menudo la posibilidad de los sujetos de narrarse de otro modo, de actuar, de decir su palabra o definirse de forma alternativa a la asignada por medio de las catalogaciones psiquiátricas. Es decir, 
el modo de operar de estos relatos produce lo que Spivak ${ }^{(20)}$ Ilama efecto de sujeto subalterno, o lo que es lo mismo, sitúa a las personas en un orden de vida que podría considerarse inviable ${ }^{(21)}$.

Si se pretende actuar para transformar situaciones como las que se vienen caracterizando, resulta imprescindible desbaratar lo que se ha convertido en un saber establecido y rígido a fin de facilitar demandas que de otro modo serían imposibles. Butler ${ }^{(18)}$ sugiere dos caminos en esta dirección orientados al reconocimiento efectivo de sujetos viables, de cuerpos y vidas vivibles: por un lado, apunta la pertinencia del empleo del lenguaje para afirmar condiciones de vida aceptables en las que sea posible la afirmación de un rol constitutivo en la vida política. Por otro lado, apunta la exploración o revisión crítica de las propias categorías empleadas. Ambas vías incluyen la posibilidad de apropiación del lenguaje -sea este científico, técnico o lego-, y de abrirlo a nuevas significaciones. Para la autora estadounidense, si el sujeto se construye en el lenguaje y a partir de normas sociales previas a él que rigen un mundo que no ha escogido, entonces su agencia reside en aquello que el sujeto hace con dichas normas y sus relatos ${ }^{(18,22,23)}$. En otras palabras, la viabilidad del "yo" depende de la capacidad del ser de hacer algo con lo que se hace con él.

Si como argumenta Freire ${ }^{(19)}$ "el lenguaje que utilizamos para hablar de esto o de aquello y la forma en que testificamos están [...] atravesados por las condiciones sociales, culturales e históricas del contexto en el que hablamos y damos testimonio", entonces cambiar el lenguaje es cambiar el contexto. Uxía proporciona un ejemplo elocuente de esta posibilidad, al afirmar lo siguiente:

Intento siempre desmedicalizar todas estas cuestiones. Llevarlas a un terreno de... "a cualquiera nos puede pasar... esto realmente no es tan diferente, no es tan extraordinario..." porque lo que quiero es quitarle tragedia al tema. Pienso que este tema de la esquizofrenia en particular, de las llamadas enfermedades mentales en general, tiene muchísimo de tragedia y muy poco de comprensión. O sea, mucho de medicalización, de tecnicismo, mucho de medicación por supuesto, de psicofarmacología y todo eso, en detrimento de comprender esto como experiencias humanas.

La lucha por la transformación de las condiciones de negación de los sujetos pasa, por tanto, por el lenguaje utilizado, por cómo se utiliza y por los sentidos que se le otorga. Ahí reside según Butler la posibilidad de la crítica y la apertura a nuevas formas de reconocimiento de la diferencia que se resiste a los modelos de asimilación. En sus palabras "esta es la coyuntura de la cual emerge la crítica, entendiendo la crítica como un cuestionamiento de los términos que restringen la vida con el objetivo de abrir la posibilidad de modos diferentes de vida" ${ }^{(18)}$. Desde este punto de vista términos como esquizofrenia o psicosis, si bien invocan normas cuya desviación produce identidades deterioradas o negadas, dicho lenguaje no deja de estar marcado tanto por su contexto social como por la capacidad de cuestionarlo y subvertirlo. Teniendo esto en cuenta, otras posiciones subjetivas pueden ser posibles a partir de la resignificación del lenguaje y la apertura de nuevos escenarios, "hablando de maneras que aún no han sido legitimadas $y$, por tanto, produciendo nuevas y futuras formas de legitimación"(23). Sin embargo, es preciso no olvidar que la condición de sujeto implica justamente también la sujeción a las normas que regulan lo que se considera el habla de un sujeto. Situarse en los márgenes de dichas normas supone riesgos que no deben obviarse puesto que en ese límite es donde se va a situar la locura:

Colocarse fuera del campo de lo enunciable supone poner en peligro el estatuto de uno mismo como sujeto. Asumir en el propio habla las normas que regulan lo enunciable significa adquirir el estatuto de sujeto de discurso. El "discurso imposible" serían precisamente los laberintos 
de lo asocial, los delirios del "psicótico" que es producido por las normas que regulan el campo de lo enunciable ${ }^{(23)}$.

Esto plantea la cuestión de cuál es el discurso lógico y qué es lo razonable, qué puede considerarse decible dentro de este marco, quién lo define, bajo qué criterios, etc. En definitiva exige distinguir qué merece ser tenido en cuenta, puesto que de ello depende la posibilidad de ser de numerosas subjetividades disidentes con las normas establecidas. Y es que, de nuevo con Butler, "las condiciones mismas de inteligibilidad han sido formuladas en y por el poder, y este ejercicio normativo del poder rara vez es reconocido como una operación del poder"(23).

Vista la polémica con que se relacionan distintas formas de dar cuenta de la locura, interesa avanzar en las consecuencias de entender este concepto como fundamentalmente controvertido apuntadas por Geekie y $\operatorname{Read}^{(1)}$, articulándolas a través de la noción de reconocimiento.

Desde dicho enfoque, se tratará de establecer una serie de condiciones que pongan a la perspectiva socioeducativa sobre la pista de una actuación en salud mental que posibilite nuevos tránsitos a los sujetos en la construcción de sus propias biografías e historia social, desde sus propios sentidos y significados $y$, en fin, desde su propia autoría. Esto incluye admitir de forma efectiva y $\sin$ reservas incluso aquello que produce extrañeza o inquieta, justo porque se define en sus propios términos y no mediante cualquier forma de lenguaje impuesto.

\section{La pluralidad}

Resulta evidente que entender un concepto como fundamentalmente controvertido implica admitir la existencia de una multiplicidad de formas de definirlo y emplearlo. Supone reconocer aquello que según Arendt ${ }^{(24)}$ hace posible la realidad y garantiza su persistencia: la pluralidad humana. Esta perspectiva posibilita el acercamiento a lo diferente, a lo desconocido o a lo extraño, en una actuación que requiere colaboración entre disciplinas, profesionales, personas afectadas y legas en la materia, pues de lo que se trata es de admitir diferentes formas de experimentar y/o nombrar procesos que son diversos. Se trataría de no sentir la necesidad de refutar, anular o invisibilizar la pluralidad implícita en la locura, avanzando así en su comprensión.

No obstante, cabe observar con relación a la aceptación de la pluralidad, cómo en algunos de los terrenos en que se abordan cuestiones de salud mental no se consideran igualmente aptos a todos los agentes para contribuir a la definición de problemas o necesidades asociados al sufrimiento psíquico. Conviene destacar la funcionalidad en el plano de la gestión de los servicios, de delimitar sectores específicos de actuación supuestamente homogéneos y aplicar el esquema problema-necesidades-recursos. En este sentido, siguiendo a Canals ${ }^{(3)}$, en los sistemas de salud mental y servicios sociales se da por sentado quién es competente, posee la autoridad, el criterio y el saber al respecto y quién no. En palabras del autor:

\begin{abstract}
Quien define problemas, identifica necesidades y aplica recursos es el agente encargado de su gestión, mientras que las personas afectadas nunca se definen a sí mismas y, en caso de hacerlo, se arriesgan a recibir etiquetas suplementarias, generalmente de carácter psicopatológico, si su autodefinición no implica la aceptación propia de los diagnósticos técnicos.
\end{abstract}

Esta falta de consideración en dichos sistemas hacia quienes reciben un diagnóstico psiquiátrico y sus opiniones, ha sido ampliamente denunciada tanto por parte de las personas usuarias como desde el ámbito de la investigación crítica en este terreno ${ }^{(25)}$.

Además, una racionalidad instrumental semejante, se contradice con el respeto recíproco exigido a las personas por el tipo de racionalidad que, inscrita en la esfera de la interacción comunicativa, se propone reconocer la pluralidad. Desde esta última, lo 
que se postula es que, aun siendo distintos, todos los sujetos merecen un trato igual en su diferencia a efectos de generar un tipo de inclusión no niveladora ni cosificadora del otro en su alteridad ${ }^{(26)}$. De hecho, el reconocimiento de la pluralidad en el marco de un tipo de acción regida por la comprensión intersubjetiva, exige aceptar la igual manifestación de quien es diferente, más aún cuando en tales procesos se producen identidades y subjetividades, tanto de palabra como de acción ${ }^{(27)}$.

Para ello resulta precisa una actitud crítica en el seno de las profesiones autodefinidas como relacionales, encargadas de la actuación técnica en salud mental. Se ha podido constatar en este sentido que "las asimetrías existentes demuestran que lo relacional no incluye necesariamente lo dialógico"(3), de modo que la jerarquía de saberes sigue instaurada tanto en los servicios sociales como en el sistema de salud mental. Es más, según Ortiz ${ }^{(8)}$, los procesos de marginación y exclusión a que continúan siendo sometidas las personas "objeto" de diagnósticos técnicos tienen lugar y se instalan en los mismos ámbitos de la atención profesional.

La expulsión de la voz narrativa del sujeto de la aflicción ha sido motivo, para Iria, de un profundo malestar. Es más, en su opinión se trata de una actitud:

\begin{abstract}
...muy fascista, porque yo estuve en un hospital, dije que me quería suicidar y lo que hicieron conmigo fue no tenerme en cuenta, no tenerme en cuenta porque lo único que hicieron fue darme pastillas. Si yo quería suicidarme sería por algo, y allí no habló ningún psicólogo conmigo. Más bien parecía que me estaban castigando, que te portas mal, que ¿quién eres tú para decir que te quieres suicidar?
\end{abstract}

Por su lado, Lois expresa el modo en que su punto de vista y su voluntad nunca se han tenido en cuenta en el hospital psiquiátrico en el que vive desde hace dos décadas. Subraya que:

Pueden castigarte por ejemplo por quedarte dormido y no ir al comedor, a lo mejor te dejan sin cobrar o, jostras!, si no comes te dejan castigado, si no barres te dejan castigado... y así, y por tonterías de estas... no me gustaba la verdad, me ponía en contra de eso y salía perdiendo yo siempre. Salía perdiendo porque no eres quien, no mandas ná. Ellos lo mandan todo y tú no mandas ná.

Frente a la exclusión, el menosprecio o el autoritarismo en la atención, se defiende la necesidad de que la controversia de la locura caiga en un terreno de interacciones subjetivas, simétricas y dialógicas, en que las personas puedan mostrarse en su diferencia aun cuando puedan existir desacuerdos con los criterios diagnósticos y técnicos de los saberes expertos. De este modo, se entiende que puede encaminarse un reconocimiento y una aceptación reales de la pluralidad, que entren de lleno en el abordaje de cuestiones complejas como lo es la locura.

\section{La complejidad}

Aceptar que el término locura remite a un concepto fundamentalmente controvertido implica además el reconocimiento de los factores sociales, culturales, políticos y psicológicos que contribuyen a la postura adoptada por individuos, grupos e instituciones $^{(1)}$. Para comprender las razones por las cuales los sujetos adoptan una visión particular de la esquizofrenia, no solo conviene prestar atención a la idea en sí, sino también a los factores internos y contextuales -sociales, políticos, culturales-, que confluyen en la construcción de -o la adhesión a-, tal o cual idea. Resulta en este punto interesante acudir a Snow et al. ${ }^{(28)}$, quienes toman prestado de Goffman el término de marcos de referencia para aludir a los esquemas interpretativos a partir de los cuales las personas y/o colectivos construyen identidades y ubican, perciben, identifican y clasifican los acontecimientos ocurridos dentro de su espacio de vida y en el mundo en general. En salud mental se generan constantemente procesos de expansión de marcos de 
referencia, se crean puentes entre esquemas interpretativos diversos, etc., dependiendo de variables tales como las relaciones que se entablen con la industria farmacológica, en el sistema de salud mental o entre los movimientos sociales. En este inter-juego se produce lo que Menéndez ${ }^{(29)}$ denomina transacciones entre el modelo médico hegemónico, los grupos y modelos que subalterniza y las resistencias o alternativas posibles.

De acuerdo con lo expuesto, investigar los factores que influyen en la forma particular de interpretar la locura tal vez contribuya a una compresión más profunda de la realidad en que las personas diagnosticadas y sus familias están inmersas, así como a establecer criterios de actuación conjuntos. En este sentido, Xián comenta que:

...cada persona es un mundo, condi-
cionado por un contexto social, político,
económico, religioso, militar... y, en este
contexto, llamémosle comunitario, se
incluye también la situación familiar del
enfermo mental. [Así, resulta imposible
comprender la locura] al margen de la
cultura, al margen de la familia, de la
violencia que también puede ser causa
de un cuadro psicótico, y de la misma
comunidad, de la sociedad en la que se
mueve un enfermo mental que empieza
a estar esquizofrénico.

Pero la complejidad de elementos que interactúan y contribuyen a la aparición del malestar resulta a menudo ignorada en el marco de la atención al sufrimiento psíquico. Iria expone este aspecto al relatar la manera en que, tras cada ingreso hospitalario, la devolvían de nuevo, cargada de pastillas:

...exactamente al mismo lugar donde mi abusador sexual podía andar por ahí, al mismo lugar donde yo seguía siendo pobre, al mismo lugar donde percibía la lesbofobia... ¿eso es aportar en salud mental? En todo caso creo que, si no estaba loca, me volvieron en el hospital.
Factores tales como las creencias y valores, la postura sociopolítica e ideológica, cuestiones de género, el imaginario personal de la locura, las biografías personales, los grupos de afinidad o los espacios de participación social, influencian las hermenéuticas de las personas afectadas, tanto como las de quienes investigan o actúan profesionalmente en este campo $^{(1)}$. En definitiva, es la misma sociedad y su complejidad lo que se expresa a través de los diferentes modos en que se concibe, aborda y nombra la locura.

\section{La disconformidad}

Otra de las consecuencias de comprender la locura como concepto en esencia controvertido es que permite focalizar la atención hacia el propósito y las funciones asociadas al uso de los términos. Si uno de los objetivos de la educación es la restauración de la intersubjetividad y el diálogo, se vuelve una exigencia problematizar las situaciones en que se niega a las personas expresarse en sus propios términos, disentir e incluso romper, para ser más ${ }^{(30)}$. Sin embargo, nuevamente en los ámbitos en que se aborda profesionalmente la locura, se elaboran constantemente diagnósticos que definen y clasifican unilateralmente a las personas en categorías de "diferentes" para, después, someterlas por lo general a procesos de normalización a través de la aplicación de programas estandarizados. Al decir de Canals ${ }^{(3)}$ :

Tales instituciones son, ciertamente, lugares de construcción y legitimación de diferencias y alteridades. Pero al mismo tiempo, su discurso central subraya el objetivo de superar los efectos y estigmas de la diferencia, a veces mediante el ambiguo concepto de normalización. Este último no deja de plantear ciertas inconsistencias en sus usos más habituales: sin negar cierto derecho a la diferencia, pretende incorporar a los diferentes a los mismos parámetros de "normalidad" que han funcionado como referentes para establecer, precisamente, su condición de diferentes. 
Para construir un mundo en el que la diferencia tenga un lugar real, inteligible y viable, resulta imprescindible deconstruir previamente la hegemonía naturalizada, también en educación, de la ficción de lo normal ${ }^{(31)}$-el cuerpo normal, el pensamiento, leguaje y comportamiento normal, etc.-, admitiendo la posibilidad de lo inesperado e imprevisible, sin sentir la necesidad de patologizarlo.

Sin embargo, la crítica a este régimen normativo no siempre es bien acogida en los circuitos de salud mental. Iria denuncia la constante insistencia por parte del personal de los servicios de salud, orientada a minimizar cualquier discrepancia posible:

"Esto es lo que hay y no te puedes rebelar", porque eso realmente es lo que me dijeron a mí y a muchísima gente [...] Te venden eso de que lo que tienes es que estar tranquila, que como que no te puedes hacer cargo de tus necesidades y, bueno, que estás mal si estás así muy reivindicativa.

También Roi comenta que, al tratar de discontinuar la medicación y evitar con ello los graves efectos secundarios que le ocasionaba, se encontró con que lejos de apoyarlo, su médico le advertía en tono amenazante: "a ver si vuelves a tomarlas [las pastillas], ique a mí no me gusta ir a buscar a la gente brotada por ahí!".

Más allá del reconocimiento efectivo de la diferencia en la construcción de una lógica dialógica, Habermas ${ }^{(26)}$ ha señalado que es condición sine qua non para establecer la situación ideal de diálogo, el acuerdo pactado en torno al significado de los conceptos y prácticas. Tal situación ideal sería aquella en que las personas gozaran de una posición simétrica para defender argumentativamente sus puntos de vista e intereses, de forma que el consenso resultante no se debiera a la coacción o al control, sino a la fuerza del mejor argumento.

No obstante, el avance en el reconocimiento de la diferencia tal y como aquí se plantea, y del mismo modo que ya apuntó
Geertz $^{(32)}$ con relación a la antropología interpretativa, guarda una orientación más pragmática. Es decir, se trata menos de alcanzar la situación ideal de consenso que de admitir las diferentes posturas en relación de simetría. Lo indica Uxía:

No se trata de pasar del punto de vista especializado, rechazarlo completamente, sino mirarlo de una forma crítica. O sea, está el punto de vista especializado, pero también está poner en valor el tuyo propio. En este caso tu propio conocimiento de ti misma, de los propios recursos, en este caso mentales o psicológicos, para enfrentar una serie de cosas. Ponerlos en valor.

Como se ha visto, las consecuencias de entender un concepto como esencialmente controvertido tienen un alcance que apunta hacia el respeto efectivo de la pluralidad y la complejidad del fenómeno de la locura. Ello implica tanto el manejo de significados, usos y propósitos diversos, como la aceptación de las múltiples influencias -psicológicas, sociales, culturales, etc.-, contenidas en los diferentes marcos de referencia que adoptan individuos, grupos e instituciones en el abordaje, comprensión e interpretaciones de la locura.

Dirigir la atención a la función que desempeña el uso de los términos en la interacción y el debate, e intentar ver si se promueve o no con ellos el respeto a la diferencia una vez asignada -como sucede en el caso de la tan coreada y no siempre problematizada, normalización-, supone no obviar que en ocasiones los etiquetamientos diagnósticos no son elegidos por quienes los reciben. Esto exige reconocer, cuando no privilegiar, de haberlos, el disenso o la disconformidad, pues forman parte constituyente e indisociable de la pluralidad y la complejidad de la esquizofrenia, la psicosis o la locura, como concepto.

Una última forma de reconocimiento derivada de la controversia de la locura, tiene que ver con el valor de las experiencias en primera persona y con el de las narrativas que de ellas se desprenden. 


\section{Saberes y relatos desde la experiencia}

En parte, la polémica que rodea a la locura tiene que ver con la variedad o multiplicidad de experiencias a las que se alude. Incluso las marcas diagnósticas que se inscriben en los cuerpos bajo rótulos como el de esquizofrenia, produciendo identidades patológicas, emergen de las narrativas de las personas que experimentan sufrimiento mental. Conviene destacar la importancia de que sea el propio sujeto quien comparta su experiencia, pues es desde esta expresión y su relato desde donde se construye el sentido de las distintas visiones e interpretaciones de la locura. A partir de la narración del sujeto se describen sus síntomas, se emiten diagnósticos que lo clasifican o se adoptan medidas terapéuticas. Sin el relato en primera persona sería impensable la catalogación de ciertas experiencias bajo rúbricas psiquiátricas, pues estas solo son posibles en virtud de las informaciones verbales, comportamentales o actitudinales que expresan los cuerpos.

Hay que destacar que lo que permite hablar desde la experiencia $-y$ aunque esta sea frecuentemente negada por las instancias encargadas de elaborar conocimiento en materia de locura-, es su legitimidad incontestable. Como señala Pié( ${ }^{(33)}$, en esta legitimidad reside también el potencial político y disruptivo que en educación pueden tener las narrativas en primera persona. En opinión de la autora:

Lo que permite hablar desde la experiencia es, justamente, que el relato o narrativa no pueden deslegitimarse. Por otro lado, la potencia política y disruptiva que tiene cualquier enunciado formulado desde la experiencia es mucho más contundente que el que pueda tener una formulación elaborada desde el supuesto teórico.

Los saberes hechos de experiencia se constituyen y sedimentan en cuerpos atravesados por numerosas tramas de significados interpersonales a partir de las que se dota de sentido la vida ${ }^{(34,27)}$. Teniendo esto en cuenta,
Uxía se muestra profundamente escéptica con la perspectiva hegemónica referida al sufrimiento psíquico cuando afirma:

Evidentemente yo no soy partidaria de la perspectiva biologicista. Toda mi vida es una demostración, o sea, va en contra de la teoría biologicista. Porque si finalmente la teoría biologicista estuviese en lo cierto [...] yo no podría estar manteniendo esta conversación contigo sin medicarme. Estaría ya en crisis, ingresada, delirando, diciendo incoherencias y teniéndote miedo, ¿entiendes? Entonces, como que no [sonríe]. Digamos que no me vale a mí ese modelo de entendimiento.

$\mathrm{Si}$ la experiencia narrada en primera persona y su relato no pueden deslegitimarse, se exige entonces también el reconocimiento sin reservas de los saberes y el potencial político que contienen. Cualquier actuación socioeducativa orientada al cambio debe tomar esto en consideración, y respetar que la iniciativa para la transformación de las situaciones concretas que oprimen, invalidan o invisibilizan a los sujetos, debe partir de los propios grupos subalternos: el papel de la educación crítica es constituirse en herramienta para que esto ocurra ${ }^{(19,30,34)}$. Roi reivindica el potencial de las personas que han vivido el malestar a la hora de ayudar a otras con sus saberes hechos de experiencia ${ }^{(30)}$. Sostiene por ejemplo que:

Una persona que sea adicta, que haya sido adicta, puede ayudar yo creo que bastante bien... de que se interesa por el tema y tiene información y puede ayudar a otra persona para que siga el proceso. Y a lo mejor el loco, de una forma diferente, o lo que sea, también. A mí me parece un valor ahora mismo.

Por otro lado, las relaciones en que nos conformamos y constituimos como personas, cuya vivencia forma parte indisociable de cualquier relato biográfico, tienen un carácter parcialmente irrecuperable. En otras 
palabras, la experiencia tiene un carácter ciertamente fragmentario cuando se trata de capturarla en el discurso y de compartirla a través de la narración. Desde este punto de vista resulta imposible trasladar al presente la totalidad de acontecimientos a partir de los que cada cual se constituye como sujeto. En este sentido las personas dan cuenta de sí mismas mediante el relato ante otras, pero ese dar cuenta se relaciona con experiencias más o menos remotas que dependen del entorno y cuya recuperación es posible solo hasta un punto.

Butler conecta esta dimensión parcial de la narración con los vínculos de dependencia al advertir que "si nos formamos en el contexto de relaciones que resultan parcialmente irrecuperables para nosotros, la opacidad parece estar incorporada a nuestra formación y es consecuencia de nuestro estatus de seres constituidos en relaciones de dependencia"(22). Desde este punto de partida la autora propone una teoría acerca de la formación del sujeto que indica claramente los límites del autoconocimiento, fundamentando una concepción de la ética y de la responsabilidad que pone el acento en la necesidad de los vínculos relacionales y subraya la imposibilidad de pensarse o narrarse al margen de ellos.

Se impone, por tanto, la necesidad de establecer la escena de la interpelación para que el reconocimiento de la experiencia y con esta, el saber del "otro/a", puedan tener un lugar efectivo, posibilitando decididamente la emergencia de nuevos significados, nuevas lógicas y nuevas prácticas que contribuyan a una mejor comprensión de la locura.

La hegemonía del modelo médico, hay que recordarlo, se produce no como algo natural o estático, sino como un proceso dinámico en permanente relación con los discursos y prácticas de los grupos a los que subalterniza en un determinado momento histórico ${ }^{(29,35)}$. Pero tal y como ha indicado Foucault( ${ }^{(36)}$, allí donde hay poder hay también resistencia.

Como se tratará de mostrar, la apuesta por un tipo educación inquieta por subvertir el orden de cosas actual en salud mental, se encuentra mucho más cerca de la lógica de actuación de los movimientos sociales de lo que de aquella que opera en instituciones totales o en algunos de los dispositivos y recursos de la red sociosanitaria. $Y$ ello en parte porque cuestiones tales como la lucha por el reconocimiento en las distintas formas señaladas, así como el apoyo mutuo, la reciprocidad o la simetría, han sido elementos constantes en la praxis histórica de los primeros ${ }^{(37,38)}$, cuya puesta en práctica ha facilitado la producción de significados y subjetividades disidentes con la norma hegemónica.

En este marco, el ensayo de otras formas posibles de relacionarse con el sufrimiento, priorizando la experiencia y el testimonio como fuentes de evidencia, es un hecho que no debe pasar desapercibido en la investigación. Las ignorancias respecto del "otro/a", de la subalternidad, no representan tanto una falta de conocimiento sino el efecto de una determinada manera de conocer ${ }^{(39)}$.

Esta lucha se considera de enorme importancia a la hora de informar lógicas alternativas y/o críticas con el modelo médico hegemónico, puesto que su predominancia no se da de forma unilateral. Antes, al contrario, se insiste en que supone conflictos $y$, en ocasiones, genera su radical cuestionamiento ${ }^{(35)}$.

\section{La locura como lugar de enunciación política}

Conviene insistir en que la apropiación y el cuestionamiento del lenguaje degradante u ofensivo mediante el que se designa y clasifica a las personas, se relaciona con la misma persistencia del "yo" que, como diría Sartre, depende de la capacidad del ser de hacer algo con lo que se hace con él. La agencia no consiste, por tanto, en negar la propia condición de objeto de burla o menosprecio, ni tampoco aquello que señala la diferencia disparando los niveles de vulnerabilidad. Más bien, la agencia deriva de toda esa serie de patrones no escogidos -sociales, políticos, económicos, etc.- que conforman 
y designan a las personas como desviadas, discapacitadas o enfermas mentales, pero también de la capacidad de mantener con ellos una relación potencialmente subversiva. Siguiendo a Butler, "el 'yo' que soy se encuentra constituido por normas y depende de ellas, pero también aspira a vivir de manera que mantenga con ellas una relación crítica y transformadora"(22). Cabe apuntar, sin duda, que "no se trata de minimizar el dolor que se sufre a causa del lenguaje de odio, sino de dejar abierta la posibilidad de su fracaso, puesto que esta apertura es la condición de una respuesta crítica"(22) que habilite otras posiciones y formas de circular socialmente. Con este objetivo, en la experiencia de Uxía fue necesario visibilizar su diagnóstico: "utilizando la expresión que utilizan en las luchas por los derechos sexuales, salir del armario. Era validar. Saliendo del armario validas con tus actuaciones y con tus palabras, tu vida". De la mano del activismo político en salud mental, hoy emplea esta estrategia como forma de construcción de un tipo de orgullo loco. Hoy no se avergüenza al decir:

Tengo este diagnóstico y no me impide hacer todo lo que hago, no me impide nada. Soy así y tengo este diagnóstico. Es una forma de validarlo y de darle luminosidad, de alejarlo de todo este modelo de la tragedia personal que es al que se remite siempre la discapacidad en general, la diversidad funcional.

Esta lógica de actuación que ha sido denominada como "queer"(40), radica en la enunciación de la abyección como base para su oposición y cuestionamiento, adquiriendo todo su poder precisamente a través de la invocación reiterada que relaciona un concepto dado con acusaciones, patologías e insultos ${ }^{(41)}$. Queer, en inglés, reúne toda una serie de expresiones peyorativas tales como, anormal, raro, desviado o trastornado, las cuales sitúan al cuerpo no normativo fuera del espacio público, en un régimen de invisibilidad. Este movimiento de exclusión relega a quien no se ajusta a la normalidad, a una posición a partir de la que se van a elaborar toda una serie de taxonomías que clasifican y describen dichos cuerpos como diferentes, estereotipándolos. El estereotipo opera en este sentido como simplificación al dar por supuesta una forma fija o detenida de representación, toda vez que niega el verdadero juego de la diferencia.

Señala Bhabha ${ }^{(42)}$ que esto constituye un problema para la visibilización de los sujetos en significaciones de relaciones psíquicas y sociales que son siempre mutables, variables. Pero la modernidad ha conseguido inscribir estas representaciones de forma estática en los cuerpos, a partir de la construcción de binomios naturalizados y esencializantes (normal-anormal, sano-enfermo, capacitadodiscapacitado, cuerdo-loco, etc.), bajo la apariencia de la verdad científica.

Como se expone a continuación, esta ilusión es firmemente contestada tanto desde este enfoque queer como desde algunas de las lógicas de actuación que, en el terreno de los movimientos sociales y la salud mental, buscan combatir el autoestigma, los prejuicios y las identidades deterioradas asociadas a la locura. El testimonio de Iria lo sugiere cuando afirma que:

Conocí a otras mujeres lesbianas y su discurso, que me sirvió para tomar parte. También el discurso de diversidad funcional. Conocí a quien fue mi pareja, una mujer trans, y eso también me ayudó muchísimo, ver la lucha trans, la lucha por la despatologización, en contra de la psiquiatrización. Y un poco también romper con los esquemas de dos sexos, dos géneros y romper con el esquema de lo que es cordura y lo que es locura.

Según Britzman ${ }^{(43)}$, la teoría queer es un compromiso con una serie de principios que pueden caracterizarse de transgresores, perversos y políticos. Transgresores, porque cuestionan los efectos de los binarismos en que se basa el régimen normativo; perversos, porque rechazan su utilidad reclamando la desviación como ámbito de interés; y políticos porque rechazan, a su vez, la utilidad de las leyes y prácticas instituidas por este 
sistema de oposiciones duales. Es decir, la teoría y prácticas queer se apropian de un espacio abierto a la reconstrucción donde se cuestionan y proclaman las identidades subversivas y raras, revelando la falta de reflexión en torno a la normalidad. Asimismo, la injuria que significa queer es apropiada y empleada como un lugar de enunciación política y de oposición radical a la norma y a las políticas tradicionales de la identidad.

De otro modo, puede afirmarse que esta perspectiva representa una mirada crítica respecto a los procesos de construcción de las subjetividades. Desde ella se ha venido cuestionando la constitución de las identidades de género tanto como la construcción de los sexos o los deseos, considerándolas dinámicas, complejas y variables. Además de ellas, otras categorías que marcan subjetividades van a ser puestas en tela de juicio al relacionarlas con determinados organizadores sociales estructurales generadores de opresión y al pensarlas, por tanto, en términos de poder y de interacciones simbólicas ${ }^{(44)}$. En ningún caso se comprenden como cuestiones esenciales, naturales o estrictamente biológicas.

En este sentido, la locura como categoría identitaria unívoca va a ser puesta en cuestión tanto en la práctica como en los discursos de una gran parte de los colectivos reunidos bajo el paraguas del movimiento de personas usuarias, ex usuarias y supervivientes de la psiquiatría. Tal y como apunta Spargo ${ }^{(45)}$ el término queer está siendo continuamente reelaborado para cambiar los contextos sociales y discursivos en los que tradicionalmente viene siendo empleado, con el objetivo de diversificar el alcance de los temas y métodos propuestos desde la teoría. Aunque, generalmente, esté vinculado al análisis de las cuestiones referidas a la sexualidad, cada vez más se examina este concepto "en relación con otras categorías de conocimiento que contribuyen a mantener relaciones de poder harto desiguales: la raza, la religión, la nacionalidad, la edad y la clase"(45).

En la misma línea argumental, Mérida coincide en que más allá de las reivindicaciones asociadas a la lucha por el reconocimiento de los derechos sexuales y a los estudios de lesbianas, gays, bisexuales y transexuales (LGTB), en la actualidad, el movimiento queer está ampliando "su radio de acción a entramados sociales de nuevo calado o a cuestiones vinculadas, por ejemplo, a la raza, la religión, la ecología y a los grupos marginados por el capitalismo globalizador de fines del siglo XX"(46).

Asimismo, Butler confirma esta lógica expansiva considerando la necesidad del uso combativo del término y su naturaleza dinámica e inclusiva en nuevos ámbitos de actuación. En su opinión "deberá permanecer ese término que, en la actualidad, nadie posee del todo, y que debe ser constantemente resistematizado, distorsionado, desviado de usos anteriores y dirigido hacia apremiantes objetivos en expansión"(41).

Teniendo esto en cuenta, hay que señalar que si bien el término "locura" -junto con sus derivados y sinónimos- se ha empleado frecuentemente de manera despectiva, "Ios últimos años han sido testigos de varios intentos de 'rescate de la locura' por parte del movimiento de los usuarios de servicios de salud mental, del mismo modo que gays y lesbianas han rescatado el uso de 'marica'"(1). De acuerdo con lo expresado, Roi sostiene que:
...es exactamente como el mundo gay, es lo mismo. Como era antes el tema de los gays. O sea, era una cosa ahí tabú, pro- hibida, no sé... era como todo chungo y terrible. Pues es un poco lo mismo. [...] estamos hablando ya, de orgullo loco.

Es en esta línea argumental que Iria sugiere que las personas diagnosticadas:

...deberíamos aprovecharnos mucho de lo que hicieron las feministas, las lesbianas y gays, porque prácticamente el discurso es muy parecido. Las estrategias van ser muy parecidas, así que una parte del trabajo podemos considerar que la tenemos hecha.

Como se ha indicado, desde algunos movimientos sociales integrados por personas con diagnóstico psiquiátrico, tal y como 
ocurre en caso de los movimientos Mad Pride, Hearing Voices, The Icarus Project o Flipas GAM, se viene utilizando el concepto de locura como método de reapropiación de la experiencia, apostando por el uso politizado de un término lego en lugar de uno médico. A través de esta estrategia de enunciación que cita el término como base para su cuestionamiento, se ha conseguido abrir la posibilidad de realizar contribuciones significativas a todas las personas, incluidas principalmente aquellas que viven la locura en carne propia. Todo ello vehiculando una crítica al modelo biomédico de atención en salud mental y a su narrativa patologizadora y estigmatizante. Respecto de Hearing Voices, Uxía cuenta sobre esta red en la que se integra el colectivo en el que participa:

Hearing Voices es una referencia en el sentido de que consiguen que la gente cambie su relación con esas voces que escucha, o en relación a la paranoia o a las ideas autorreferenciales, que seguro son muchísimo más frecuentes de lo que la gente quiere reconocer. [...] Funciona mucho con el apoyo mutuo, con la comprensión y la expresión de este tipo de cosas. Expresarse, comunicarse, comprenderse, buscar alternativas para otras formas de relación, y bueno... desmedicalizarlas también.

De lo que se trata con estos ensayos no es de restar importancia al componente de sufrimiento asociado tantas veces a la experiencia de la locura. Más bien al contrario, se busca destacar que el punto de vista biomédico no tiene por qué ostentar el monopolio del saber con relación a la aflicción, y que el reconocimiento y el respeto de otras formas de enunciación de estas vivencias subjetivas deben no solo ser posibles, sino que debieran asimismo ser tomadas seriamente en cuenta en distintos espacios colectivos y de atención. En todo caso, desde numerosas iniciativas dentro del movimiento de personas usuarias, ex usuarias y supervivientes de la psiquiatría se está abriendo un espacio para el cambio en el uso del sistema de signos imperante, que operan una serie de transacciones ${ }^{(20,37)} \mathrm{O}$ desplazamientos semánticos que indican la complejidad de la relación entre el modelo médico hegemónico y ciertos modelos alternativos emergentes.

En cuanto a las taxonomías del saber médico-psiquiátrico, tantas veces inaccesible a la comprensión profana o popular, esta lógica transaccional -entendida como capacidad de acción- funciona como oposición a un lenguaje que aliena al individuo de su experiencia, colonizándola y contribuyendo sin duda a incrementar exponencialmente su sufrimiento ${ }^{(1)}$. Conviene advertir, no obstante, que tal y como señala Uxía:

\begin{abstract}
Desmedicalizar es un discurso que no conviene, porque claro, hay muchos médicos viviendo de que todo esto sea medicalizable... entonces no es un discurso que se vaya a promover desde las plataformas del mundo de la salud mental, porque no es lo más conveniente. Pero bueno.
\end{abstract}

La apropiación del lenguaje guarda, en cualquier caso, el sentido de una estrategia que podría considerarse de re-eslabonamiento de la cadena de signos continua propuesta por la narrativa biomédica, que anuncia la crisis del modelo hegemónico ${ }^{(20)}$. Así, donde el saber médico emplea un término clínico, el saber profano acude a uno popular. Donde la psiquiatría habla de trastornos y síntomas, los colectivos de personas diagnosticadas hablan de experiencias humanas subjetivas. La identidad patológica y sus roles asociados -enfermo/a, paciente, usuario/a, etc.-, también cambian aquí en favor de una identidad dinámica y un rol activo, co-productor de significados diversos a partir de la propia experiencia. Lo indica Iria claramente al afirmar de sí misma:

Hay mucha gente que habla de que son como supervivientes de la psiquiatría, yo me considero que no soy únicamente superviviente de la psiquiatría, más bien de todo un sistema que hay alrededor: una superviviente del capitalismo. 
Lo que interesa es, en definitiva, situar los saberes contenidos en estas experiencias en una relación de simetría con los saberes técnicos y científicos. En otras palabras, interesa rescatar para el debate y en sus propios términos los saberes sometidos, aunque expertos desde la experiencia, que atesoran las personas que han vivido o viven la aflicción, en una apuesta dialógica sin restricciones. Dichos contenidos culturales son los que deben poder ponerse en juego y transmitirse en la tarea socioeducativa referida al sufrimiento.

\section{[IN]CONCLUSIÓN}

El desafío pues, para la investigación y acción socioeducativas, no es otro que el de facilitar las condiciones de posibilidad para articular este espacio de diálogo, admitiendo otros lenguajes y lógicas de actuación a través de los que reconocer la diferencia sin menospreciarla, asimilarla o fiscalizarla. Es decir, respetándola sin tutelas. En este sentido la resignificación o performatividad del lenguaje plantea este reto al requerir la apertura de nuevos escenarios, hablar desde formas que pueden no estar todavía legitimadas y, por lo tanto, generar nuevas y prometedoras vías de legitimación ${ }^{(22)}$. De otro modo, se busca desplazar las posiciones hegemónicas de enunciación y reclamar la legitimidad de otros relatos y prácticas significantes posibles de los cuerpos parlantes ${ }^{(47)}$.

Un acercamiento, como el expuesto a lo largo de estas páginas, a un tipo de identidad que no presuponga esencias, a sujetos en proceso, pone de manifiesto el potencial de las prácticas queer en la comprensión de las relaciones entre identidad, acción y discurso, de forma menos rígida y excluyente de lo que admiten la lógica biomédica y sus nomenclaturas cerradas. El propósito no es otro que el de dar "cabida a la agencia individual y colectiva, a fin de oponer resistencia a los saberes y prácticas opresivos sin volver a la idea modernista del sujeto autónomo"(45).

Por decirlo de otro modo, se hace necesario tomar en consideración los cuerpos y su gestión en el marco de la experiencia del sufrimiento humano, más allá de los criterios de la racionalidad instrumental ${ }^{(48)}$. A partir de ahí se entiende que es posible la apertura hacia nuevos sentidos y significados críticos con cualquier forma de dominación. Lo que interesa a la pedagogía social, desde este punto de vista, no es sino la habilitación o multiplicación de estos espacios, caminos y relatos, desde donde hacer $-y$ compartir- experiencia.

\section{REFERENCIAS BIBLIOGRÁFICAS}

1. Geekie J, Read J. El sentido de la locura. Barcelona: Herder; 2012.

2. Álvarez J. La invención de las enfermedades mentales. Madrid: Gredos; 2008.

3. Canals J. Ambigüedades y contradicciones sobre la diversidad en los ámbitos de la salud mental y de los servicios sociales. En: Comelles M, Bernal M. Salud mental, diversidad y cultura. Madrid: Asociación Española de Neuropsiquiatría; 2008.

4. Martínez A. Antropología médica: Teorías sobre la cultura, el poder y la enfermedad. Barcelona: Anthropos; 2011.
5. Lafuente A, Alonso A, Rodríguez J. ¡Todos sabios!: Ciencia ciudadana y conocimiento expandido. Madrid: Ediciones Cátedra; 2013.

6. Correa M. Radio nikosia: La rebelión de los saberes profanos; otras prácticas, otros territorios para la locura. Tarragona: Universitat Rovira i Virgili, Departament d'Antropologia, Filosofia i Treball Social; 2010.

7. Veiga K. Artesaos da saúde: Saúde mental e participaçao social em porto alegre. Tarragona: Universitat Rovira i Virgili, Departament d'Antropologia, Filosofia i Treball Social; 2011.

8. Ortiz A. Hacia una psiquiatría crítica. Madrid: Grupo 5; 2013. 
9. Joseph J. La esquizofrenia y la herencia. En: Read J, Mosher L, Bentall R. Modelos de locura. Barcelona: Herder Editorial; 2006.

10. Read J. La invención de la "esquizofrenia". En: Read J, Mosher L, Bentall R. Modelos de locura. Barcelona: Herder Editorial; 2006.

11. Cooke A, Basset $T$, Bentall R, Boyle $M$, Cupitt C, Dillon J, et al. Comprender la psicosis y la esquizofrenia: ¿Por qué a veces las personas oyen voces, creen cosas que a otros les parecen extrañas, o parecen estar fuera de la realidad, y qué es lo que puede ayudarles? Canterbury: Canterbury Christ Church University; 2015.

12. Geekie J. Escuchar las voces que oímos. En: Read J, Mosher L, Bentall R. Modelos de locura. Barcelona: Herder Editorial; 2006.

13. Bentall R. Renunciar al concepto de esquizofrenia. En: Read J, Mosher L, Bentall R. Modelos de locura. Barcelona: Herder Editorial; 2006.

14. Wittgenstein L. Conferencia sobre ética. En: Gómez C. Doce textos fundamentales de la ética del siglo XX. Madrid: Alianza Editorial; 2007.

15. Salas Soneira M. Acción socioeducativa y locura: Tramas, narrativas y experiencias en el ámbito de la salud mental en Galicia. [Tesis de doctorado]. Barcelona: Universidad de Barcelona; Departamento de Teoría e Historia de la Educación; 2017.

16. Bertaux D. Los relatos de vida: Perspectiva etnosociológica. Barcelona: Ediciones Bellaterra; 2005.

17. Guha R. Prefacio a los estudios de la subalternidad: Escritos sobre la historia y la sociedad surasiática. En: Rivera S, Barragán R. Debates Post Coloniales: Una introducción a los estudios de la subalternidad. La Paz: Aruwiyiri; 1997.

18. Butler J. Deshacer el género. Barcelona: Ediciones Paidós Ibérica; 2006.

19. Freire $P$. Cartas a quien pretende enseñar. Buenos Aires: Siglo XXI Editores; 2004.

20. Spivak G. Estudios de la subalternidad: deconstruyendo la historiografía. En: Rivera S, Barragán R. Debates Post Coloniales: Una introducción a los estudios de la subalternidad. La Paz: Aruwiyiri; 1997.

21. Asensi M. La subalternidad borrosa: Un poco más de debate en torno a los subalternos. En: Spivak G. ¿Pueden hablar los subalternos? Barcelona: MACBA; 2009.
22. Butler J. Dar cuenta de sí mismo: Violencia ética e identidad. Buenos Aires: Amorrortu Editores; 2009.

23. Butler J. Lenguaje, poder e identidad. Madrid: Editorial Síntesis; 2009.

24. Arendt H. ¿Qué es la política? Barcelona: Ediciones Paidós; 1997.

25. Chamberlin J. Servicios dirigidos por los usuarios. En: Read J, Mosher L, Bentall R. Modelos de locura. Barcelona: Herder Editorial; 2006.

26. Habermas J. Ética discursiva. En: Gómez C. Doce textos fundamentales de la Ética del siglo XX. Madrid: Alianza Editorial; 2007.

27. Arendt H. La condición humana. Barcelona: Paidós Surcos; 2005.

28. Snow DR. Procesos de alienamiento de marcos, micromovilización y participación en movimientos. En: Chihu Amparán A. El "análisis de los marcos" en la sociología de los movimientos sociales. México: Porrúa; 2006.

29. Menéndez E. Modelo médico hegemónico y atención primaria. En: Segundas Jornadas de Atención Primaria de la Salud. Buenos Aires: Grupo Editor de las Jornadas; 1988.

30. Freire P. Pedagogía del oprimido. Madrid: Siglo XXI Editores; 2012.

31. Skliar C. Acerca de la alteridad, la normalidad, la anormalidad, la diferencia, la diversidad y la pronunciación de lo educativo. Gestos mínimos para una pedagogía de la diferencia. En: Angelino M, Almeida M. Debates y perspectivas en torno a la discapacidad en América Latina. Paraná: Universidad Nacional de Entre Ríos, Facultad de Trabajo Social; 2012.

32. Geertz C. La interpretación de las culturas. Barcelona: Gedisa Editorial; 2006.

33. Pié A. La dimensión política de la dependencia. En: Pié Balaguer A. Deconstruyendo la dependencia: Propuestas para una vida independiente. Barcelona: Editorial UOC; 2012.

34. Freire P. Pedagogía de la esperanza: un reencuentro con la pedagogía del oprimido. México: Siglo XXI Editores; 1992.

35. Menéndez E. Hacia una práctica médica alternativa: Hegemonía y autoatención (gestión) en salud. En: Campos R. Antropología médica en México 1. México: Instituto Mora-UAM; 1992. 
36. Foucault M. Microfísica del poder. Madrid: Ediciones La Piqueta; 1978.

37. Menéndez E. El modelo médico hegemónico: transacciones y alternativas hacia una fundamentación teórica del modelo de autoatención en salud. Arxiu d'etnografía de Catalunya. 1984;(3):84-119.

38. Lehmann P. Alternativas a la Psiquiatría. Revista de la Asociación Española de Neuropsiquiatría. 2013;33(117):137-150.

39. Lopes G. Teoría queer-uma política pós-identitária para a educaçao. Revista de Estudos Feministas. 2001;(2):541-553.

40. Gamson J. ¿Deben autodestruirse los movimientos identitarios?: Un extraño dilema. En: Mérida R. Sexualidades transgresoras: Una antología de estudios queer. Barcelona: Icaria; 2002.

41. Butler J. Críticamente subversiva. En: Mérida Jiménez R. Sexualidades transgresoras: Una antología de estudios queer. Barcelona: Icaria; 2002.
42. Bhabha $\mathrm{H}$. El lugar de la cultura. Buenos Aires: Manantial; 2002.

43. Britzman D. La pedagogía transgresora y sus extrañas técnicas. En: Mérida R. Sexualidades transgresoras: Una antología de estudios queer. Barcelona: Icaria; 2002.

44. Platero R. Intersecciones: cuerpos y sexualidades en la encrucijada. Barcelona: Ediciones BeIlaterra; 2012.

45. Spargo T. Foucault y la teoría queer. Barcelona: Editorial Gedisa; 2007.

46. Mérida R. Sexualidades transgresoras: Una antología de estudios queer. Barcelona: Icaria; 2002.

47. Preciado B. Manifiesto contrasexual. Barcelona: Editorial Anagrama; 2011.

48. Pié A. Por una corporeidad postmoderna: Nuevos tránsitos sociales y educativos para la interdependencia. Barcelona: Editorial UOC; 2014.

FORMA DE CITAR

Salas Soneira M. Usos de [la] locura: hacia el reconocimiento de nuevas lógicas interpretativas del sufrimiento humano. Salud Colectiva. 2017;13(4):713-729. doi: 10.18294/sc.2017.1613

Recibido: 17 de octubre de 2017 | Versión final: 14 de noviembre de 2017 | Aprobado: 28 de noviembre de 2017

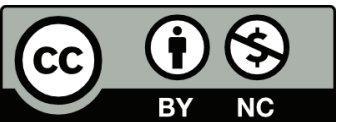

Este obra está bajo una licencia de Creative Commons Reconocimiento-NoComercial 4.0 Internacional. Reconocimiento - Permite copiar, distribuir y comunicar públicamente la obra. A cambio, se debe reconocer y citar al autor original. No Comercial - Esta obra no puede ser utilizada con finalidades comerciales, a menos que se obtenga el permiso. 